\title{
Crown root fracture imaging on Cone Beam Computed Tomography
}

\author{
Anak Agung Gde Dananjaya Agung ${ }^{1 *}$, Ni Ketut Ayu Lestarini²
}

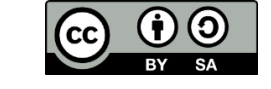

This work is licensed under a
Cheative Commons Attribution Wich permits use, distribution and reproduction provided that the origininal work is roproperly cited,
the use is non-commercial and no modifications or adaptations are made.
and
${ }^{1}$ Department of Dentomaxillofacial Radiology, Dental Education Study Program, Faculty of Medicine, Universitas Udayana, Denpasar, Indonesia 80361

${ }^{2}$ Dental Education Study Program, Faculty of Medicine, Universitas Udayana, Denpasar, Indonesia 80361

${ }^{*}$ Correspondence to:

Anak Agung Gde Dananjaya Agung $\bowtie$ agungdananjaya@unud.ac.id

Received on: October 2021 Revised on: November 2021 Accepted on: December 2021

\section{ABSTRACT}

Objectives: This case report is aimed to describe the features of $C B C T$ in assessing tooth fracture.

Case Report: A 50-year-old man came with complaints of discomfort in the right lower jaw area, especially when used for chewing. The results of the percussion test were positive. CBCT examination showed that there was a radiolucent image of the enamel in the middle of the crown root to the $1 / 3$ apical of the mesial and distal roots of tooth 47 which resembled a fracture line. The fracture line also appears to have reached the pulp. In addition, there is a well-defined radiolucent appearance with an irregular shape along the root from the buccal to lingual alveolar crest and accompanied by a decrease in the alveolar crest. The fracture that occurred in this case was from the enamel to the apical and involved the pulp, thus the radiodiagnosis on tooth 47 was a complicated crown root fracture with lateral periodontal cyst.

Conclusion: CBCT can be used to help identify tooth fractures by obtaining a more accurate and useful value in differentiating conditions associated with fractures. CBCT provides data on the size and length of the fracture line and the size of the lesion.

Keywords: Cone beam computed tomography, crown-root fracture, lateral periodontal cyst

Cite this article: Agung AAGD, Lestarini NKA. Crown root fracture imaging on Cone Beam Computed Tomography. Jurnal Radiologi Dentomaksilofasial Indonesia 2021;5(3)112-7. https://doi.org/10.32793/jrdi.v5i3.738

\section{INTRODUCTION}

Traumatic dental injuries (TDIs) often occur with sufficient frequency high in preschool, school and young adults. The highest frequency of tooth fracture is at the age of $17-25$ years $(53,5 \%)$ and the lowest is at the age of $46-55$ years $(1,8 \%) .{ }^{1}$ While in children the highest fracture frequency is at the age of 9 years $(47,37 \%)$, followed by the age of 10 years $(24,56 \%)$ and the lowest at the age of 11 years $(7,02 \%)^{2}$ Based on the gender, men have more potential for dental trauma than women. ${ }^{3}$ This is also supported by a research which shows that the frequency of tooth fractures in men is higher than in women. ${ }^{1}$

Around $25 \%$ of tooth fractures in permanent teeth and $40 \%$ in primary teeth are caused by traumatic injury. The most common event responsible for the fracture of permanent teeth is a fall, followed by accidents involving vehicles (e.g., bicycles, automobiles) and blows from foreign objects striking the teeth. Fractures involving only the crown normally fall into three categories there were fracture that involve only the enamel without the loss of the enamel substance, fracture that involve enamel or enamel and dentin with loss of tooth substance but without pulp involvement (uncomplicated fracture), and fracture that pass through enamel, dentin, and pulp with loss of tooth substance and exposure of the pulp (complicated fracture). ${ }^{4}$ The classification of trauma according to World Health Organization (WHO) are crown infarction, crown fracture, root fracture, and crown root fracture that can involve the pulp is called complicated while that which does not involve the pulp is called uncomplicated. ${ }^{5}$

A crown root fracture is a fracture involving the crown and root. The frequency of complicated crown root fractures are $0.9 \%$ while uncomplicated crown root fractures are $0.7 \%{ }^{1}$ In crown root fracture, the permanent teeth are affected about twice as much as the deciduous teeth, and most crown root fracture of the anterior teeth are the result of direct trauma, while many posterior teeth are predisposed to such fractures by large restorations or extensive caries. Crown root fractures occasionally manifest with bleeding from the pulp. In addition, because these teeth are sensitive to occlusal forces which can lead to fragment separation, a patients with crown root fracture usually complains of pain during mastication. ${ }^{4}$

In general, clinical and radiographic symptoms are not pathognomonic, which makes the diagnosis of fracture a challenge. The most frequently used diagnostic modality for tooth fractures is periapical radiography, but it has low diagnostic accuracy and cannot detect all parts of the fracture. ${ }^{6}$ Periapical 
radiographs provide a two-dimensional representation of three-dimensional anatomical structures, so the tooth and surrounding structures can mask the fracture especially if the beam does not cross the fracture line. CBCT has been used fo the diagnosis of root fractures to overcome the inherent weakness of anatomical superimposition of two-dimensional radiographs. CBCT has enabled practitioners to visualize teeth three-dimensionally and with high spatial resolution. CT and CBCT can provide better visualization of the fracture line through multi planar reconstruction images (axial, coronal, and sagittal planes). Recent studies have demonstrated the superiority of CBCT in detecting root fractures, there are some limitations to imaging when high-density materials such as guttapercha and intracanal metal posts are present. These materials can create artifacts that impair $\mathrm{CBCT}$ image quality. ${ }^{7,8} \mathrm{CBCT}$ can provide clinicians or dentists with a wide area for evaluation of tooth fractures, cracks, measurement of periapical lesions, assessment of bone density in the area of the lesion, endodontic surgery, implant planning, and analysis of temporomandibular joint and resorption. ${ }^{9}$

The objective of this report is to describe the features of $\mathrm{CBCT}$ in assessing tooth fracture.

\section{CASE REPORT}

A 50-year-old male patient came to the dental clinic with complains of discomfort in the right lower jaw area especially when used for chewing or mastication. The result of the percussion test was positive. After that the patient was referred for a

\section{D CBCT radiology examination}

In CBCT multi-slice coronal view (Figure 1), there is a radiolucent line from the enamel in the middle of the crown to the apical distal root of tooth 47 resembles a fracture line. In addition, there is a well-defined radiolucent appearance with an irregular shape along the root from the buccal to the lingual alveolar crest with an area of \pm 66.67 $\mathrm{mm}$. In the coronal view of tooth 47 (Figure 2), there is a radiolucent line from the enamel to the apical $1 / 3$ of the mesial root and the distal root resembles a fracture with a decrease in the alveolar crest on the buccal side. There is a well-defined radiolucent appearance with an irregular shape from the alveolar crest on the buccal to the buccal side to the lingual side with an area of $\pm 66.65 \mathrm{~mm}$ in sagittal view. It may occur as a result of bacterial invasion through fracture teeth or periodontal tissues.

In the sagittal view of tooth 47 (Figure 3), there is a radiolucent line on the mesial side of the crown from the enamel to the pulp resembles a fracture with a length of $\pm 2.22 \mathrm{~mm}$ with a decrease in the alveolar crest on the mesial side. There is a radiolucent appearance with a clear and firm boundary with an irregular shape from the mesial to distal alveolar crest on tooth 47 with an area of \pm $66.55 \mathrm{~mm}$. On the axial view of tooth 47 (Figure 4), there is a radiolucent line on the crown from mesial to distal $\pm 12.29 \mathrm{~mm}$ resembles a fracture in tooth 47 and has reached $1 / 3$ of the distal root.

The fracture that occurred in this case was from the enamel to the apical and involved the pulp, thus the radiodiagnosis on tooth 47 was a complicated crown root fracture with lateral periodontal cyst.

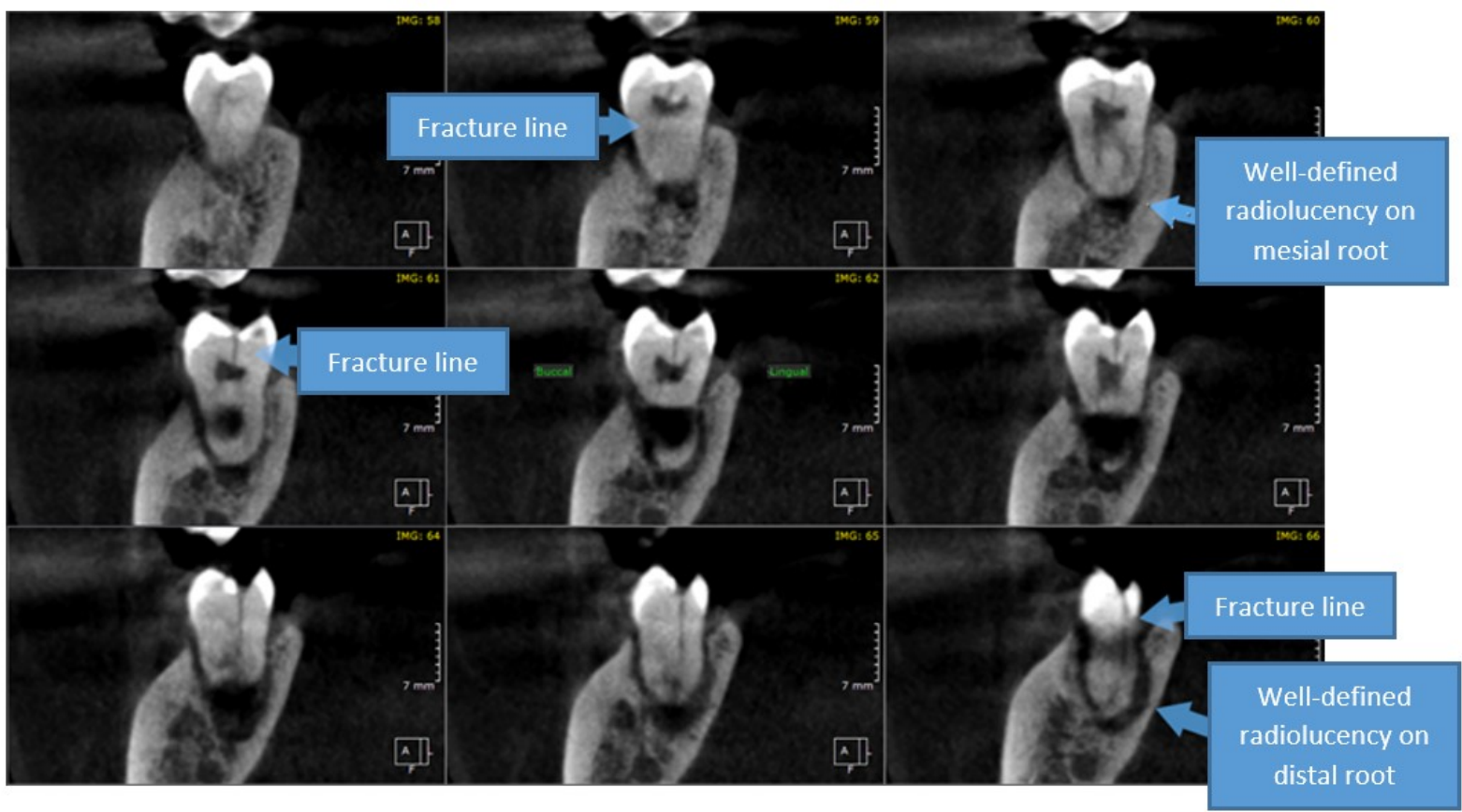

Figure 1. Multi slice coronal view in CBCT shows there is a fracture line (blue arrow) and well-defined appearance on the mesial and distal root of tooth 47 


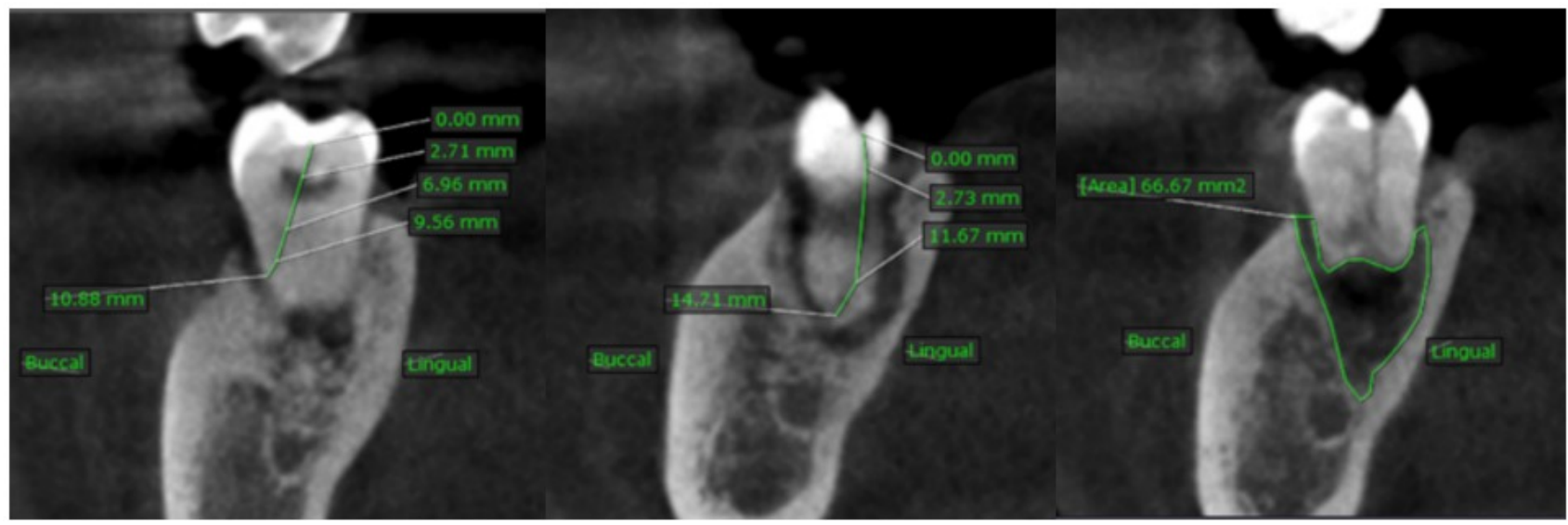

Figure 2. Coronal view in $\mathrm{CBCT}$

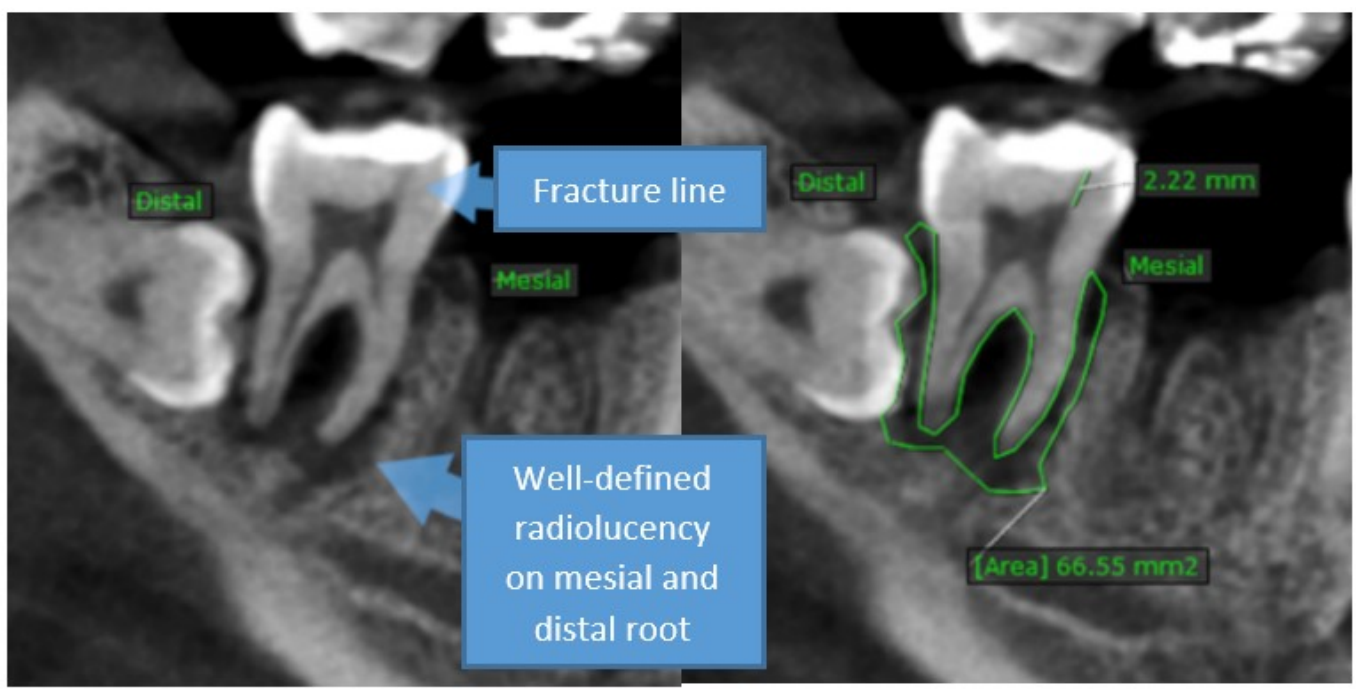

Figure 3. Sagittal view in $\mathrm{CBCT}$ shows fracture line and well-defined radiolucency on the mesial and distal root (blue arrow)

\section{DISCUSSION}

The classification of trauma according to Ellis classification consists of 9 classes, namely class 1 is an enamel fracture without or with little involvement of the dentin, class 2 is a crown fracture of the dentin without affecting the pulp, class 3 is a crown fracture involving the pulp, class 4 is the tooth being non-vital with or without loss of crown, class 5 is tooth avulsion, class 6 is root fracture with or without loss of tooth structure, class 7 is displaced tooth without crown or root fracture, class 8 is crown crushed (en mass), and class 9 is trauma to primary teeth. Classification of trauma according to the World Health Organization consists of infarcts, namely cracks in the enamel without any loss of tooth structure, root fractures, crown fractures, and crown-root fractures which are divided into complicated that is fractures involving the pulp and uncomplicated that is fractures without involving the pulp. ${ }^{5}$ In this case, the patient was diagnosed with a root crown fracture because from examination the fracture involved the root and crown.

The etiology of tooth fractures is trauma due to falls, accidents while playing, sports accidents, traffic accidents, and acts of violence. ${ }^{10}$ In this case, the patient had no history of trauma and the cause of the fracture was unknown. Based on research shows that geographic area can also be a cause of dental trauma. This relates to culture, sanitation, socio-economics, types of activities and professions, as well as ecological characteristics such as fluoride concentration in water. The prevalence of dental trauma was found to be higher in the America than Asia or Europe, it is because the activities carried out by children or adults and the fluoride concentration in areas with mild and humid weather conditions are usually low and result in low fluoride content in the teeth so that the teeth are thinner and susceptible to dental trauma. ${ }^{11}$ In addition, the etiology of cracked teeth or tooth fractures are patients who chewing too hard, eat brittle or hard foods that result in heavy occlusal forces, thermal stresses, and parafunctional habits. ${ }^{12}$

The pathogenesis of fractures, especially root fractures, is derived from the wedging forces in the canal. This excess strength exceeds the binding strength of root dentin, and causes fatigue and fracture. Irritants that cause severe inflammation of the adjacent periodontium are the result of the fracture. In general, this periodontal wreaking and the accompanying signs, symptoms, and findings 


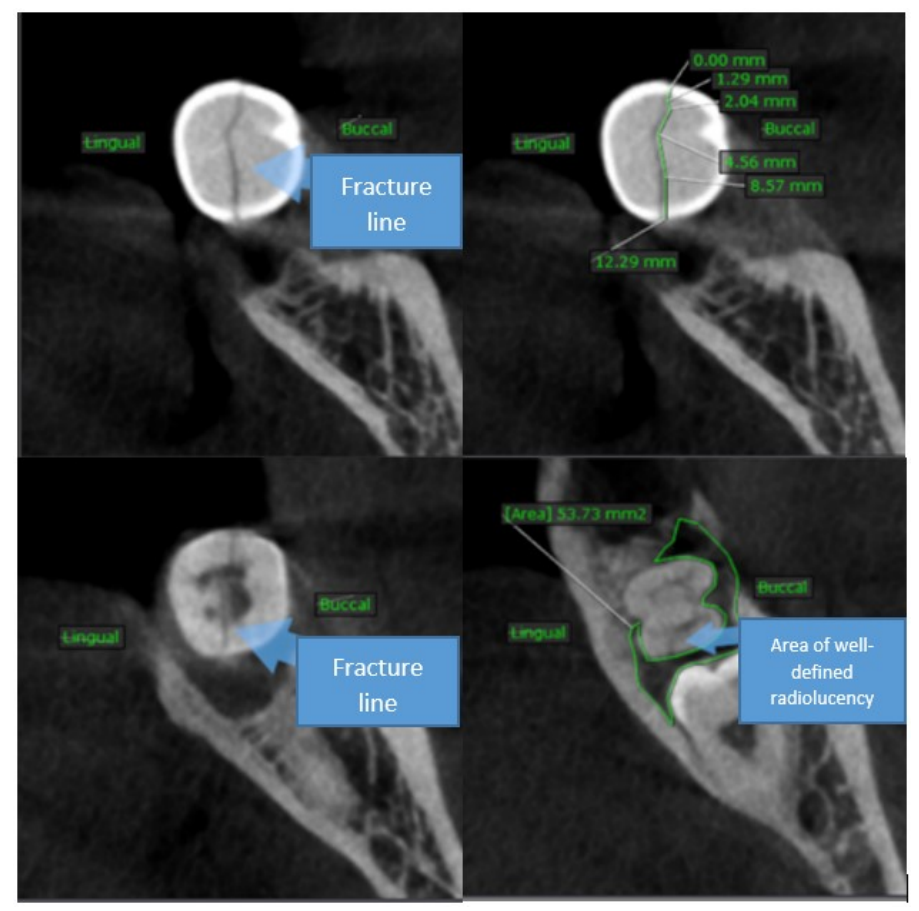

Figure 4. Axial view in CBCT shows fracture line and area of well-defined radiolucent (blue arrow)

bring the fracture to the attention of the patient or dentist. ${ }^{12}$ The presence of fractures, particularly root fractures, can provide an open pathway for bacteria between the oral cavity, root canal space, and periodontium, leading to rapid destruction of the periodontium and bone loss. ${ }^{13}$

The reported crown root fracture faced by a 50 year-old male patient. Based on research, men experience tooth fractures more often than women because they are more often involved in physical activities such as cycling, climbing, sports, and more. ${ }^{14}$ In addition, men tend to be more active so they have a higher risk of trauma than women. The highest frequency of tooth fractures is at the age of 17-25 years because at that age they do more activity and risky behavior while those over 40 years tend to have lower physical activity. ${ }^{1}$ Research shows that the maxillary central incisor anterior teeth are the most frequently traumatized..$^{15}$ Posterior teeth tend to experience vertical fractures and the highest prevalence is the maxillary second premolars and followed by the molars especially the mandibular first and second molars. Trauma to the posterior teeth usually occurs during the mastication process and is also influenced by age which affects the physiological strength of the teeth. ${ }^{1}$ In this case, the patient had a tooth fracture in the posterior tooth especially in the right mandibular second molar.

Conventional dental radiographs can be used to assist in assessing the status of the pulp and periodontium but are less effective in providing information about the direction and extent of the fracture site. Since the direction of the fracture is mesio-distal and is not sufficiently visible radiographically, thus radiographic examination is used to assist in determining the pulp and periapical status. ${ }^{12}$ Management of the fracture will vary depending on the extension of the fracture line toward the root and its relationship to the periodontium (below the alveolar crest). ${ }^{16}$ Periapical radiographs have low diagnostic accuracy

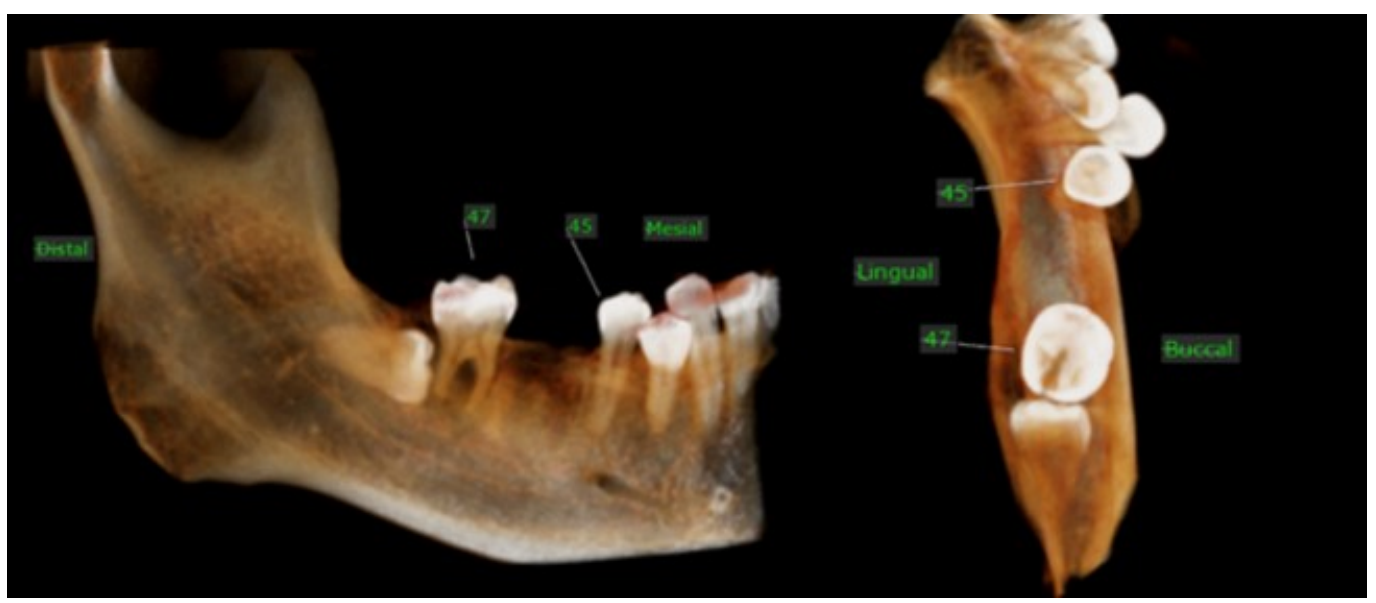

Figure 5. CBCT 3D view 
and some fractures cannot be detected. ${ }^{6}$ In addition, in two-dimensional radiography (conventional radiography) there is overlap in adjacent structures so that the visualization of the fracture line is limited. ${ }^{8}$ Conventional periapical radiographs are of limited use for the detection of fractures due to compression of three dimensional anatomical images into two dimensions, anatomic noise, and geometric distortion. Fractures are rarely seen unless separation of the root fragments has occurred and the X-ray beam coincides with the fracture plane. ${ }^{13}$

Newer analytical methods such as Cone Beam Computed Tomography (CBCT) are currently being studied to help identify longitudinal fractures by obtaining a more accurate and useful value in differentiating fracture-associated conditions such as bone loss. Cone beam computed tomography (CBCT) is a promising diagnostic method for fracture detection because it allows the tooth to be viewed in three dimensions, anatomical noise is largely eliminated and geometric distortion is minimal. Clinical studies have shown increased accuracy of CBCT compared to periapical radiographs for detecting root fractures. CBCT is more accurate than periapical radiography in detecting artificially induced vertical root fracture in extracted teeth. ${ }^{13}$ The use of CBCT radiography in dentistry allows dental practitioners to obtain three dimensional visualizations of teeth with high resolution and low radiation. Several studies have revealed the outstanding diagnostic accuracy of $\mathrm{CBCT}$ for tooth fractures, especially for fractures not detected by periapical radiographs. However, that studies based on in vitro tooth fracture and the diagnostic performance of CBCT for fractured teeth in vivo are poorly understood, and it is reported that not all dental practitioners or dental students are aware of $\mathrm{CBCT} .{ }^{6}$ СBCT showed higher diagnostic ability than conventional radiography and even $\mathrm{CT}$. In addition, СВCT provides better visualization of the fracture line through multi planar reconstructed images (axial, coronal, and sagittal planes). However, radiopaque materials such as guttapercha can create artifacts on СВCT images due to beam hardening and reduce diagnostic quality. ${ }^{8}$ In this case, a 3D CBCT radiograph was used to detect and analyze a crown root fracture in tooth 47 . The data generated not only visualized the tooth from a coronal, sagittal, or axial view, but also provided data on the size and length of the fracture line and the size of the lesion.

Management and diagnosis of complicated crown root fractures is a challenge for dentists. This is because the clinical presentation is highly variable and there are no pathognomonic signs. ${ }^{6,7}$ In addition, fracture identification also requires a combination of clinical and radiographic signs, and sometimes requires surgical findings. ${ }^{8}$ Various treatment modalities have been proposed for crown root fractures such as removing the coronal fragment and restoring it back above the gingival level, allowing the subgingival portion of the fracture to heal with the formation of a long junctional epithelium. The second treatment option is to change the subgingival fracture to a supra gingival fracture with gingivectomy and osteotomy procedures, but it produces poor esthetics so it is not suitable for anterior teeth. The third treatment option is removal of the coronal fragment and surgical extrusion of the tooth to move the fracture to a supra gingival position. In such procedures, the periodontal ligament may fail to reattach to the root surface and greatly increase the risk of root resorption. The fourth treatment option is removal of the coronal fragment and subsequent orthodontic extrusion of the tooth. ${ }^{17-18}$

In this case there was a radiographic picture of a well-defined radiolucent appearance with an irregular shape along the root from the buccal to lingual alveolar crest and a decrease in the alveolar crest so that a lateral periodontal cyst was diagnosed in tooth 47 . Tooth fractures such as vertical root fractures can be a non-physiological pathway for entry of bacteria into the tooth pulp and periodontium. ${ }^{19}$ The presence of bacteria that enter the periodontium can cause a periodontal disease and will even develop into cysts such as lateral periodontal cysts. Lateral periodontal cyst is a non-inflammatory, non-keratinized, and developmental cyst that occurs adjacent or lateral to the root of vital tooth. ${ }^{20}$ Lateral periodontal cysts are thought to arise from epithelial remnants in the lateral periodontium of the tooth root. The condition is usually unicystic, but may appear as a cluster of small cysts, a condition referred to as botryoid odontogenic cyst. ${ }^{21}$ The lesions are usually asymptomatic and less than $1 \mathrm{~cm}$ in diameter. In contras, the size of the lesion in this case is \pm 66.55 $\mathrm{mm}$. The disorder has no clear predilection, and the age distribution extends from the second to the ninth decade (mean age about 50 years). If these cysts become secondary infected, they mimic a lateral periodontal abscess. The radiographic appearance of a lateral periodontal cyst is a welldefined radiolucency with prominent cortical margins and is round or oval in shape, and large cysts that are rarely more irregular in shape. Thus, the lateral periodontal cyst in this case is quite rare because it has an irregular shape. The effect of a lateral periodontal cyst is that it can remove the lamina dura from adjacent roots, and a large cyst can move the adjacent teeth. Lateral periodontal cyst develops in the mandible mostly in region lateral incisor to the second premolar. ${ }^{4}$ In contras, this case occurred in the posterior teeth. Management for lateral periodontal cyst usually do not require sophisticated imaging because of their small size. The treatment choice for lateral periodontal cyst is excisional biopsy or simple enucleation because these cysts do not tend to recur. ${ }^{4}$

\section{CONCLUSION}

A crown root fracture is a fracture involving the crown and root. $\mathrm{CBCT}$ radiographic examination can be used to help identify tooth fractures by obtaining a more accurate and useful value in 
differentiating conditions associated with fractures. The use of CBCT radiography in dentistry allows dental practitioners to obtain three dimensional visualizations of teeth with high resolution and low radiation. CBCT showed higher diagnostic ability than conventional radiography and even CT. CBCT provides better visualization of the fracture line through axial, coronal, and sagittal planes and provided data on the size and length of the fracture line and the size of the lesion.

\section{ACKNOWLEDGMENTS}

None.

\section{FOOTNOTES}

All authors have no potential conflict of interest to declare for this article. Informed consent was obtained from the patient for being included in this case report.

\section{REFERENCES}

1. Farani W, Nurunnisa W. Distribusi frekuensi fraktur gigi permanen di rumah sakit gigi dan mulut universitas muhammadiyah yogyakarta. Insisiva Dent J Maj Kedokt Gig Insisiva. 2018;7(1):28-36.

2. Septahapsari Al, Sutadi H, Fauziah E. Distribusi frekuensi trauma gigi permanen anterior pada anak usia 8-12 tahun. Skripsi. Jakarta: Universitas Indonesia, 2014.

3. Enabulele JE, Mohammed BE. Socio-demographic distribution of adult patients who seek oral health treatment following trauma to anterior teeth. J Trauma Care. 2017;3(1):1017.

4. White SC, Pharoah MJ. Oral radiology principles and interpretation. 7th ed. St. Louis Missouri: Elsevier; 2014. p.347, 566

5. Soeprapto A. Pedoman dan tatalaksana praktik kedokteran gigi. STPI Bina Insan Mulia; 2017. p.97.

6. Long $\mathrm{H}$, Zhou $\mathrm{Y}$, Ye N, Liao L, Jian F, Wang $\mathrm{Y}$, et al. Diagnostic accuracy of $C B C T$ for tooth fractures: A meta-analysis. J Den [Internet]. 2014:42(3):240-8.

7. Ferreira LM, Visconti MAPG, Nascimento HA, Dallemolle RR,
Ambrosano GM, Freitas DQ. Influence of CBCT enhancement filters on diagnosis of vertical root fractures: A simulation study in endodontically treated teeth with and without intracanal posts. Dentomaxillofacial Radiol. 2015;44(5):2-7.

8. Hekmatian $E$, Karbasi Kheir M, Fathollahzade $H$, Sheikhi M. Detection of vertical root fractures using cone-beam computed tomography in the presence and absence of guttapercha. Sci World J. 2018;2018:1-6.

9. Doğan MS, Callea M, Kusdhany LS, Aras A, Maharani DA, Mandasari $\mathrm{M}$, et al. The evaluation of root fracture with cone beam computed tomography (CBCT): An epidemiological study. J Clin Exp Dent. 2018;10(1):e41-8.

10. Haryuni RF, Fauziah E. Penatalaksanaan fraktur Ellis kelas II gigi 11, 21 pada anak usia 9 tahun. J Indones Dent Assoc. 2018;1(1):10-6.

11. Azami-Aghdash S, Azar FE, Azar FP, Rezapour A, Moradi-Joo $M$, Moosavi A, et al. Prevalence, etiology, and types of dental trauma in children and adolescents: systematic review and meta-analysis. Med J Islam Repub Iran. 2015;29(4):234.

12. Rivera EM, Walton RE. Longitudinal tooth cracks and fractures: an update and review. Endod Top. 2015;33(1):1442.

13. Brady E, Mannocci F, Brown J, Wilson R, Patel S. A comparison of cone beam computed tomography and periapical radiography for the detection of vertical root fractures in nonendodontically treated teeth. Int Endod J. 2014;47(8):735 $-46$

14. Fidel SR, Fidel-Junior RA, Sassone LM, Murad CF, Fidel RA. Clinical management of a complicated crown-root fracture: a case report. Braz Dent J. 2011;22(3):258-62.

15. Kovács $M$, Pãcurar $M$, Petcu $B$, Bukhari C. Prevalence of traumatic dental injuries in children who attended two dental clinics in Târgu Mure between 2003 and 2011. OHDM. 2012;11(3):116-24

6. Yadav $M$, Kaushik $M$, Sharma $R$, Chowdry $P$. Minimal Invasive Surgical Approach in The management of comminuted crownroot fracture- a Case Report. J West African Coll Surg [Internet]. 2017;7(4):128-40.

17. Kulkarni V, Sharma D, Banda N, Solanki M, Khandelwal V, Airen P. Clinical management of a complicated crown-root fracture using autogenous tooth fragment: A biological restorative approach. Contemp Clin Dent. 2013;4(1):84-7.

18. Kulkarni VK, Sridhar R, Duddu MK, Banda NR, Vyawahare S, Sharma D. Biological restoration in a young patient with a complicated crown root fracture with an autogenous tooth fragment. J Clin Pediatr Dent. 2013;38(2):117-21.

19. Ismi N, Susanto A. Keterkaitan lesi endo-perio (Tinjauan Pustaka). Cakradonya Dent J. 2020;12(2):93-8.

20. Chrcanovic BR, Gomez RS. Gingival cyst of the adult, lateral periodontal cyst, and botryoid odontogenic cyst: An update systematic review. Oral Dis. 2019;25(1):26-33.

21. Whaites E, Drage N. Essentials of dental radiography and radiology. Fifth edition. St. Louis Missouri: Elsevier; 2013. p.337. 